\title{
Event Cosplay Organizer Online dengan Sistem Rekomendasi Juri Menggunakan Perbandingan Metode AHP dan SAW (Studi Kasus pada Kaze Production)
}

\author{
http://dx.doi.org/10.28932/jutisi.v5i2.1761
}

\author{
Ananda Dhammahito Adhe Herlambang ${ }^{\# 1}$, Julianti Kasih ${ }^{\varpi * 2}$ \\ S1 Teknik Informatika, Universitas Kristen Maranatha \\ Jl. Surya Sumantri No.65, Sukawarna, Sukajadi, Bandung \\ 1anandahito@gmail.com \\ ${ }^{2}$ julianti.kasih@it.maranatha.edu
}

\begin{abstract}
As a company that moves and involved inside the creative industry such as pop culture, creating and managing events, the using technology is the main thing that the company works on. Using website as the media for organizing things related to creating and managing events gives not only the company the advanced things. Besides all the simple things having an online medium also gives the easiest way to access it anywhere and creating a better security from human error such as losing document files, damage paperwork having an accessible medium could help not only amateur creator starting to create their first event but also on a professional level where they could manage their work to be more organized and safety. Event Cosplay Organizer Online with AHP and SAW recommendation system for judges will be enhanced with main features like creating the schedule for the events, methods score counting for judge recommendation system, and counting the estimation budget for the events. The aim of this application is to help users make the right choices for event cosplay.
\end{abstract}

Keywords - cosplay, event, recommendation system, organizer, website.

\section{Pendahuluan}

Sebagai perusahaan yang bergerak dalam industri kreatif khususnya event organizer untuk event cosplay, maka bagi Kaze Production merancang event dan menerapkannya dengan sukses merupakan tujuan utama perusahaan. Disadari terdapat kebutuhan untuk membangun suatu sistem yang lebih terpadu serta terkomputerisasi untuk perusahaan dan konsumennya dalam interaksi yang terjadi. Praktis, efisiensi waktu, dan meminimalkan kesalahan merupakan tujuan dari pembangunan sistem.

Pada saat ini klien Kaze Production masih harus bertemu langsung dengan pihak perusahaan untuk melakukan diskusi mengenai event yang akan dibuat. Terlepas dari penggunaan waktu yang tidak efisien dari kedua pihak, kesalahan manusia pun sering terjadi. Mulai dari data laporan yang hilang, rusak, kesalahan penulisan, informasi yang tidak tepat, dan sebagainya. Hal - hal tersebut menyebabkan proses pembuatan menjadi terhambat dan perusahaan menjadi tidak dapat mengambil semua permintaan klien yang ada dengan jumlah banyak.

Untuk merealisasikan sistem yang terpadu dan terkomputerisasi bagi perusahaan, maka dibangun sistem berbasis website dengan fitur - fitur seperti, pembuatan event cosplay, penjadwalan kegiatan acara pada event, dan sistem rekomendasi juri event cosplay..

\section{KAJIAN TEORI}

Untuk menjadi juri tentu memiliki aturan dan nilai penting yang wajib dipenuhi atau dimiliki seperti, sikap sopan, adil, jujur, dan bertanggung jawab atas keputusannya, kepribadian ini akan membentuk pengalaman bagi juri selama ia menjalankan pekerjaannya, karena seorang juri dapat dikatakan sebagai juri disebabkan oleh pengalaman yang dimilikinya dalam bidang yang bersangkutan. Sosok juri juga harus berpengetahuan luas dalam bidang yang dijurikan.[5]

Sebagai juri cosplay setidaknya harus memiliki jam terbang yang cukup banyak dalam dunia cosplay, baik dalam membuat kostum dan aksesoris cosplay, menjadi cosplay model, ataupun sering melakukan pementasan panggung cosplay yang biasa disebut dengan stage performance. [8]

Beberapa kriteria yang dijadikan tolok ukur seorang juri pada event cosplay, yaitu :

1) Pengalaman menjadi juri pada event cosplay.

2) Pengalaman dalam membuat kostum cosplay.

3) Pengalaman modeling dalam dunia cosplay.

4) Pengalaman dalam pementasan pertunjukan cosplay. 
Sebagai juri pada cosplay dilihat dari pengalamannya sebagai juri pada kompetisi-kompetisi sebelumnya yang pernah di jurikan. Bagaimana sikap juri dalam bertindak (sopan), menilai (adil dan jujur), dan memberikan keputusan (tegas, berhati-hati, dan bertanggung jawab) terhadap event atau kompetisi yang pernah ditanganinya. [8]

Pengalaman membuat kostum mencakup tentang teknik pembuatan kostum yang dikuasai dan prestasi dari hasil karya yang telah memenangkan suatu kejuaraan cosplay. Juga memahami tingkat kesulitan suatu pembuatan kostum dan jenis material yang digunakan pada kostum. [5].

Modeling dalam dunia cosplay memiliki keunikan dimana seseorang dapat menjiwai suatu tokoh yang diperankan saat difoto ataupun sedang berkeliling pada suatu event. Pengalaman pementasan berkaitan dengan kegiatan kabaret atau teater. Memiliki jalan cerita, ciri khas tokoh, vokal, intonasi, ekspresi, dan gerak tubuh menjadi kunci penilaian pada kriteria ini. [5]. Untuk menentukan event costplay dan juri berdasarkan ranking tertentu maka digunakan metode AHP yang merupakan suatu metode pendukung keputusan yang dikembangkan oleh seorang professor matematika University of Pittsburgh kelahiran Irak, Thomas L. Saaty. Dua buah metode yang diperbandingkan pada paper ini adalah AHP (Analytical Hierarchy Process) dan SAW (Simple Additive Weight).

\section{A. AHP (Analytical Hierarchy Process)}

AHP merupakan metode untuk membuat urutan alternatif keputusan dan pemilihan alternatif terbaik pada saat pengambil keputusan dengan beberapa tujuan atau kriteria Hal yang paling utama dalam AHP adalah hirarki fungsional dengan input utamanya persepsi manusia. [2]

Proses penerapan AHP yang kompleks menjadi kelemahan metode ini karena tahap yang dilakukan sangat dalam menjadikan panjangnya proses yang harus dilalui dan apabila terjadi kesalahan pada pertengahan proses, pengulangan perhitungan dari awal haruslah dilakukan kembali. [9]

Walaupun tingkat kompleksitas yang dimiliki oleh metode AHP demikian, hasil yang didapatkan dari proses panjang tersebut tentunya lebih dapat dijadikan acuan dalam suatu hitungan tujuan yang akan dicapai. Hasil yang akurat menjadi kelebihan dari metode ini. [9]

Beberapa prinsip yang digunakan pada AHP yaitu :

- Decomposition. tujuan daripada prinsip ini adalah melakukan pembagian pada masalah yang kompleks menjadi sebuah struktur dalam bentuk hirarki mulai dari pendefisian umum hingga khusus. Struktur hirarki ini berfungsi sebagai sarana untuk membandingkan antara tujuan, kriteria, dan tingkat alternatif.[2]

Gambar 1 berikut dibawah ini menjelaskan pembentukan Struktur Hirarki

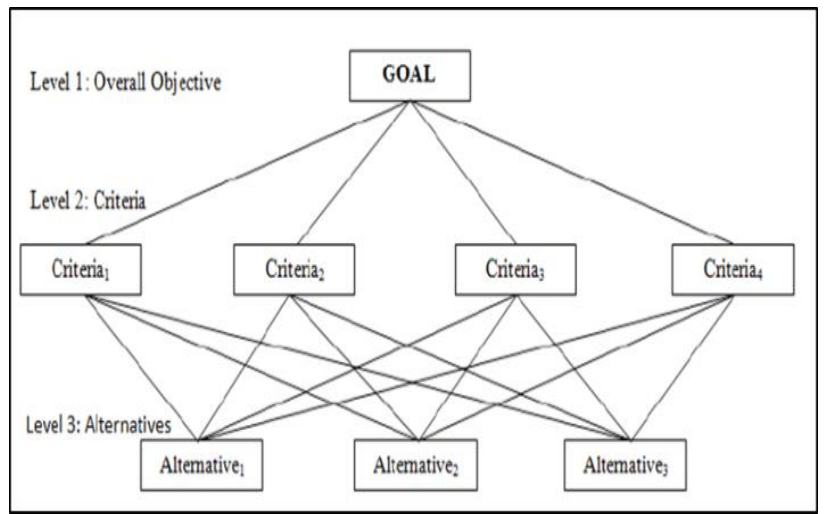

Gambar 1. Pembentukan Struktur Hirarki

- Comparative judgements prinsip ini bertujuan untuk memberikan penilaian pada kepentingan relatif dari dua elemen dalam suatu tingkat tertentu dengan tingkat yang ada diatasnya. Nilai yang digunakan diambil dari skala saaty yang nampak pada tabel I berikut.[2]

TABEL I

SKALA PERBANDINGAN SAATY

\begin{tabular}{|c|l|}
\hline $\begin{array}{c}\text { Nilai } \\
\text { Kepentingan }\end{array}$ & \multicolumn{1}{c|}{ Definisi } \\
\hline 1 & Kedua elemen sama pentingnya. \\
\hline 3 & $\begin{array}{l}\text { Elemen } x \text { sedikit lebih penting daripada } \\
\text { elemen } y .\end{array}$ \\
\hline 5 & $\begin{array}{l}\text { Elemen } x \text { esensial atau sangat penting } \\
\text { daripada elemen } y .\end{array}$ \\
\hline 7 & $\begin{array}{l}\text { Elemen } x \text { jelas lebih penting daripada elemen } \\
\text { y. }\end{array}$ \\
\hline 9 & $\begin{array}{l}\text { Elemen } x \text { mutlak lebih penting daripada } \\
\text { elemen } y .\end{array}$ \\
\hline Kebalikan & $\begin{array}{l}\text { Nilai diantara dua pertimbangan yang } \\
\text { berdekatan. }\end{array}$ \\
\hline $\begin{array}{l}\text { Jika pada perbandingan elemen x dan y } \\
\text { mendapat satu angka, maka perbandingan } \\
\text { pada elemen y dan } x \text { merupakan kebalikan } \\
\text { dari perbandingan pertama (x dan y). } \\
\text { Contoh }: \text { x dengan y bernilai 3, maka y } \\
\text { dengan } x \text { bernilai 1/3. }\end{array}$ \\
\hline
\end{tabular}

- Synthesis of priority prinsip ini memberikan matriks pairwise comparison yang kemudian dicari eigen vektornya untuk mendapatkan local priority ,yaitu tingkat kepentingan kriteria lokal yang diperlukan dalam pengambilan keputusan.[2]

- Logical consistency merupakan karakteristik yang paling penting. Hal ini dapat dicapai dengan mengagresikan seluruh vektor eigen yang diperoleh dari tingkatan hirarki dan selanjutnya diperoleh suatu vektor composite yang menghasilkan urutan pengambilan keputusan.[2] 


\section{B. Simple Additive Weight}

Metode simple additive weight atau disingkat SAW dikenal sebagai metode penjumlahan terbobot. Konsep dasar metode ini adalah mencari penjumlahan terbobot dari rating kinerja pada setiap alternatif pada semua atribut yang ada. Metode SAW membutuhkan proses normalisasi matriks pada suatu skala yang dapat diperbandingkan dengan semua rating alternatif yang ada.[6]

Kesederhanaan rumus dan penggunaannya dalam proses perhitungan pencarian keputusan akhir merupakan salah satu kelebihan utama dari metode SAW sendiri. [9]

Berikut rumus - rumus yang digunakan dalam metode SAW ini :

- Rumus normalisasi matriks

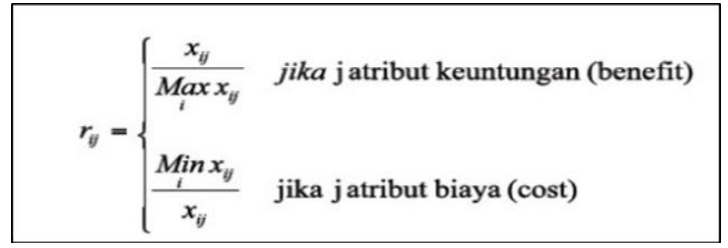

Gambar 2. Rumus Normalisasi Matriks Metode SAW

- Rumus perhitungan rangking

$$
V_{i}=\sum_{j=1}^{n} w_{j} r_{i j}
$$

Gambar 3. Rumus Perhitungan Rangking Metode SAW

Untuk menerapkan rumus pada gambar 2 dan 3 tersebut pada sebuah sistem maka digunakan bahas pemprograman PHP (Hypertext Preprocessor)

yang merupakan bahasa pemrograman script server-side yang digunakan dalam pengembangan website. PHP yang dikenal saat ini sebenarnya adalah penerus dari produk bernama PHP/FI yang dibuat oleh Rasmus Lerdorf pada tahun 1994, bentuk pertama dari PHP adalah satu set perlengkapan dari Common Gateway Interface (CGI) yang dibuat dengan bahasa pemrograman C. [1]

Sebagai metode analisis dan design berorintasi obyek digunakan Unified modeling language disingkat sebagai UML UML adalah bahasa untuk menspesifikasi, memvisualisasi, membangun, dan mendokumentasikan artifacts (bagian dari informasi yang digunakan untuk dihasilkan pada proses pembuatan perangkat lunak). Bagian - bagian utama dari UML adalah view, diagram, model element, dan general mechanism. [10]

Use case diagram merupakan salah satu model UML yang digunakan untuk menggambarkan sejumlah aktor eksternal dan hubungannya terhadap diagram. Use case adalah deskripsi fungsi yang disediakan oleh sistem dalam bentuk teks sebagai dokumentasi dari simbol diagram use case. Penggambaran pada use case hanyalah informasi yang dilihat dari luar oleh aktor dan bukan sebagaimana fungsi yang ada pada sistem. [7]

Untuk pengujian sistem yang dibangun maka Pengujian black box merupakan pengujian aspek fundamental sistem tanpa memerhatikan struktur logika internal perangkat lunak. Metode ini digunakan untuk mengetahui apakah perangkat lunak berfungsi dengan benar. Black box adalah metode perancangan data uji yang didasarkan pada spesifikasi perangkat lunak. Data uji yang dieksekusi pada perangkat lunak dan hasil keluarannya dipastikan apakah sesuai dengan hasil yang diharapkan. [4]

Pengujian black box memiliki peran secara signifikan dalam pengujian aplikasi, pengujian ini membantu secara menyeluruh fungsi validasi dari sistem. Pengujian ini dijalankan berdasarkan sudut pandang kebutuhan konsumen sebagai pengguna akhir dari aplikasi. Hal utama yang menjadi alasan dilakukannya pengujian black box adalah memastikan data masukan dari konsumen diketahui tervalidasi dan tidak tervalidasinya. [11].

\section{DESAIN DAN IMPLEMENTASI SISTEM}

\section{A. Gambaran Besar Sistem}

Dalam merealisasikan sistem yang terpadu dan terkomputerisasi bagi perusahaan dalam mengorganisir data - data event dan dapat menerima permintaan konsumen secara kolektif dengan jumlah yang banyak, maka tugas akhir ini akan membahas mengenai perancangan sistem organizer event cosplay yang berbasis website sehingga sistem dapat diakses dengan mudah dan cepat secara online.

Sistem yang dikembangkan ditujukan untuk perusahaan dalam membantu konsumennya mengorganisir perancangan event yang ingin dibuat. Pendekatan tersebut dipilih agar cakupan perusahaan dapat meraih tidak hanya konsumen yang sudah ahli dalam membuat event, namun juga yang masih pemula dalam membuat event. Dengan menyediakan form pembuatan eventyang sederhana pada website diharapkan konsumen mendapatkan gambaran secara garis besar mengenai komponen - komponen yang diperlukan dalam pembuatan event cosplay. Ditambahkan dengan adanya evaluasi lebih lanjut yang dilakukan oleh admin terhadap event yang dibuat oleh konsumen. Hal ini dilakukan agar event yang dibuat konsumen tidak mengalami keterhambatan saat proses pelaksanaan dikarenakan data yang tidak sesuai atau salah.

Proses bisnis yang dijalankan oleh perusahaan saat ini tergolong tradisional dikarenakan interaksi yang terjadi sebagian besar masih mengandalkan kontak secara langsung. Dimana kedua pihak bertemu untuk mendiskusikan acara yang ingin dibuat. Proses diawali dengan adanya permintaan dari klien dengan membawa proposal acara ke pihak perusahaan. Proposal yang masuk kemudian menunggu untuk dievaluasi lebih lanjut. Hasil evaluasi kemudian dikabarkan kepada klien melalui telepon. Apabila disetujui maka klien bertemu lagi dengan pihak perusahaan untuk mendiskusikan perlengkapan selanjutnya. Tetapi, bila tidak 
disetujui, klien memiliki dua pilihan untuk mengubah proposal yang dikira kurang, atau membatalkan proposal.

Hasil diskusi yang dilakukan antara klien dan perusahaan menyangkut masalah lokasi acara, jumlah pengunjung yang diharapkan, sound sistem yang digunakan, juri yang akan diundang, jenis lomba acara seperti apa, tingkat acara apakah membutuhkan surat pemerintah atau hanya swasta, dan biaya yang kira - kira akan dikeluarkan apakah klien dapat menyanggupi biaya tersebut.

Ketika kedua belah pihak menyetujui hasil diskusi, maka perusahaan akan mulai persiapan acara dengan menghubungi rekan eo perusahaan yang dikira sesuai dengan event yang akan dibuat. Selanjutnya lebih mengarah pada progress di lapangan, persiapan tempat, peserta, dan perlengkapan lainnya. Proses bisnis perusahaan secara garis besar seperti yang dijelaskan sebelumnya.

Pada sistem yang dibuat membutuhkan gambaran secara singkat yang digambarkan dengan use case diagram. Beberapa peran yang dimiliki oleh setiap pengguna dalam sistem akan diperlihatkan pada perancangan use case diagram yang dapat dilihat pada gambar 4 Use Case Diagram Sistem Organizer Event Costplay dibawah ini.

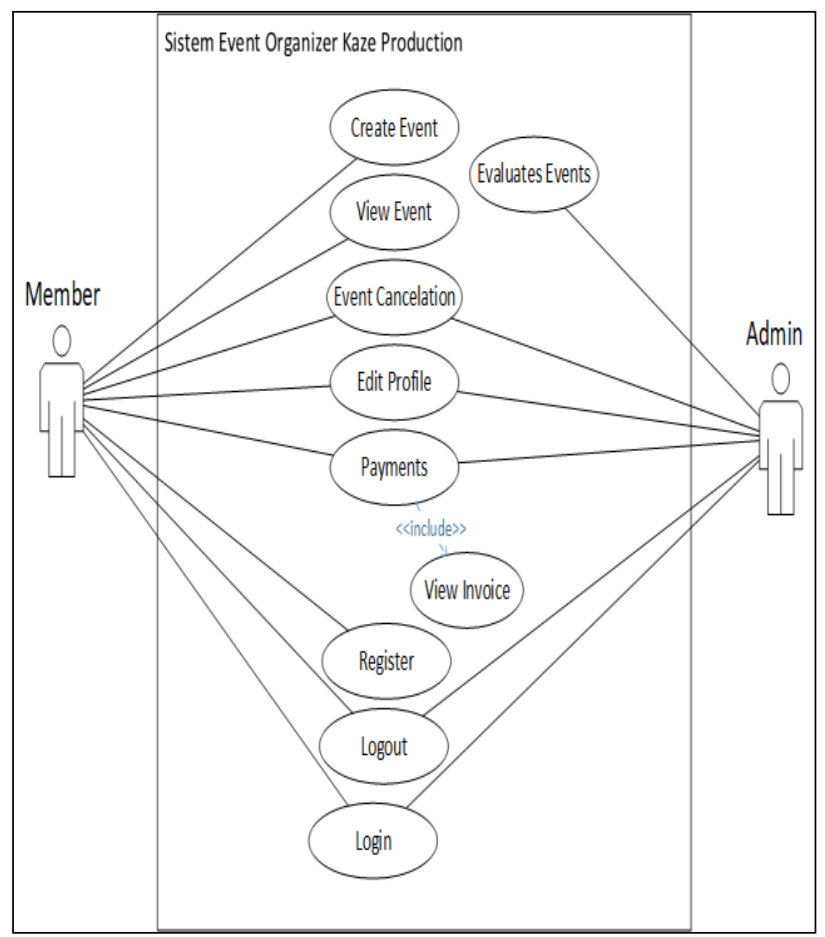

Gambar 4. Use Case Diagram Sistem Organizer Event Cosplay

Terdapat dua aktor yang berperan yaitu, member dan admin. Beberapa aksi unik yang membedakan keduanya terdapat pada admin, dimana admin memiliki aksi untuk mengevaluasi event yang dibuat oleh member. Pendukung perancangan sistem organizer event cosplay tergambarkan pada ERD yang diterapkan pada sistem basis data guna menyimpan data event sesuai dengan tipe data nya masing - masing. ERD akan ditampilkan dalam bentuk yang telah ditrnsformasikan ke dalam tabel dibawah ini.

TABEL II

TRANSFORMASI TABEL ER EVENT

\begin{tabular}{|l|l|}
\hline \multicolumn{2}{|c|}{ Nama Field } \\
\hline ID & Int(8) \\
\hline Judul & Varchar(100) \\
\hline Lokasi & Varchar(255) \\
\hline Detail_info & Varchar(500) \\
\hline Tipe_event & Int(1) \\
\hline Tgl_mulai & Date \\
\hline Tgl_akhir & Date \\
\hline Budget & $\operatorname{Int}(50)$ \\
\hline Status_event & $\operatorname{Int}(1)$ \\
\hline
\end{tabular}

Tabel II merupakan transformasi ER dari entitas event. Dimana entitas ini digunakan untuk menyimpan data yang berhubungan dengan event yang akan dibuat. Mulai dari judul event, lokasi event, detail mengenai event, tipe event (apakah daerah, nasional, atau internasional), tanggal mulai acara, tanggal akhir acara, biaya dari pembuat acara, dan status acara (apakah acara selesai, dalam proses, informasi belum lengkap).

TABEL III

TRANSFORMASI TABEL ER MEMBER

\begin{tabular}{|l|l|}
\hline \multicolumn{1}{|c|}{ Nama Field } & \multicolumn{1}{c|}{ Tipe Data } \\
\hline Email & Varchar(50) \\
\hline Password & Varchar(40) \\
\hline Nama & Varchar(255) \\
\hline Tgl_lahir & Date \\
\hline Alamat & Varchar(255) \\
\hline No_hp & Int $(13)$ \\
\hline
\end{tabular}

Transformasi ER dari entitas member ditunjukkan pada tabel III diatas.. Pada entitas ini disimpan data mengenai member sebagai pengguna yang terdaftar pada sistem antara lain, email, kata sandi, nama, tanggal lahir, alamat tinggal, dan nomor hp yang dapat dihubungi.

TABEL IV

TRANSFORMASI TABEL ER ADMIN

\begin{tabular}{|l|l|}
\hline \multicolumn{1}{|c|}{ Nama Field } & \multicolumn{1}{c|}{ Tipe Data } \\
\hline Email & $\operatorname{Int}(8)$ \\
\hline Password & Varchar(100) \\
\hline Nama & Varchar(255) \\
\hline Role & Varchar(500) \\
\hline No_hp & Int(1) \\
\hline
\end{tabular}

Tabel IV merupakan transformasi dari entitas admin. Entitas ini akan menyimpan data mengenai admin yang terdaftar pada sistem yaitu, email, kata sandi, nama admin, role (apakah admin sebagai pemilik atau staf admin), dan nomor hp. Role pada admin digunakan untuk membedakan admin menjadi 2 yaitu, admin dan super admin. Perbedaan keduanya terletak pada super admin, dimana memiliki fitur 
khusus untuk melihat keuangan terhadap data acara. Berikut adalah tabel $\mathrm{V}$ transformasi entitas event organizer

TABEL V

TRANSFORMASI TABEL ER EO

\begin{tabular}{|c|c|}
\hline Nama Field & Tipe Data \\
\hline ID & $\operatorname{Int}(8)$ \\
\hline Nama_eo & Varchar(100) \\
\hline Detail_eo & Varchar(500) \\
\hline
\end{tabular}

TABEL VI

TRANSFORMASI TABEL ER JURI

\begin{tabular}{|l|l|}
\multicolumn{1}{|c|}{ Nama Field } & \multicolumn{1}{c|}{ Tipe Data } \\
\hline Nickname & Varchar(100) \\
\hline Nama & Varchar(255) \\
\hline Bio_singkat & Varchar(500) \\
\hline Ttl & Varchar(100) \\
\hline JK & Varchar(2) \\
\hline
\end{tabular}

Tabel VI merupakan transformasi tabel entitas juri yang menyimpan data yang berkaitan dengan juri. Antara lain, nama panggilan juri, nama asli juri, biografi singkat juri, tempat dan tanggal lahir juri, dan jenis kelamin juri.

TABEL VII

TRANSFORMASI TABEL ER PERFORMA SAW

\begin{tabular}{|c|c|}
\hline Nama Field & Tipe Data \\
\hline ID & $\operatorname{Int}(8)$ \\
\hline Keahlian_membuat & $\operatorname{Int}(3)$ \\
\hline Keahlian_modeling & $\operatorname{Int}(3)$ \\
\hline Keahlian_perform & $\operatorname{Int}(3)$ \\
\hline Skor_total & $\operatorname{Int}(3)$ \\
\hline Total_menjuri & $\operatorname{Int}(3)$ \\
\hline Rating & $\operatorname{Int}(1)$ \\
\hline Id_juri_fk & Varchar(100) \\
\hline
\end{tabular}

Transformasi dari entitas performa dijelaskan pada tabel VII yaitu performa yang menggunakan perhitungan metode SAW. Entitas ini menyimpan data nilai yang digunakan untuk melakukan proses perhitungan nilai akhir dengan metode SAW. Data yang disimpan antara lain, ID, keahlian membuat (berupa nilai), modeling (berupa nilai), perform (berupa nilai), skor total(hasil perhitungan akhir), total menjuri (pernah menjadi juri berapa kali), rating (skor bernilai $1-5)$, dan id juri fk (diambil dari id juri).

Pada Tabel VIII berikut ini menjelaskan Transformasi dari entitas performa yang menggunakan perhitungan metode AHP. Entitas ini menyimpan data nilai yang akan digunakan untuk proses perhitungan skor akhir dengan metode AHP. Data yang disimpan antara lain, ID, keahlian membuat (berupa nilai), modeling (berupa nilai), perform (berupa nilai), skor total(hasil perhitungan akhir), total menjuri (pernah menjadi juri berapa kali), rating (skor bernilai $1-5)$, dan id juri fk (diambil dari id juri).
TABEL VIII

TRANSFORMASI TABEL ER PERFORMA AHP

\begin{tabular}{|l|l|}
\hline \multicolumn{1}{|c|}{ Nama Field } & \multicolumn{1}{c|}{ Tipe Data } \\
\hline ID & $\operatorname{Int}(8)$ \\
\hline Keahlian_membuat & $\operatorname{Int}(3)$ \\
\hline Keahlian_modeling & $\operatorname{Int}(3)$ \\
\hline Keahlian_perform & $\operatorname{Int}(3)$ \\
\hline Skor_total & $\operatorname{Int}(3)$ \\
\hline Total_menjuri & $\operatorname{Int}(3)$ \\
\hline Rating & $\operatorname{Int}(1)$ \\
\hline Id_juri_fk & Varchar(100) \\
\hline
\end{tabular}

Untuk membantu konsumen lebih dalam lagi, dalam suatu event cosplay terkadang memerlukan adanya juri untuk keperluan penilaian pemenang lomba cosplay, maka dirancang juga sistem rekomendasi yang berisikan daftar juri yang berasosiasi dengan perusahaan sesuai dengan rangking yang diperoleh dari hasil perhitungan metode AHP dan SAW. Dari rekomendasi juri tersebut konsumen dapat melihat rating kinerja yang diperoleh oleh masing - masing juri pada daftar. Sehingga memudahkan konsumen untuk mengambil keputusan dalam menentukan juri yang akan didatangkan pada event yang bersangkutan. Penerapan kedua metode memiliki tahapan proses yang mirip yaitu, menentukan kriteria dari juri cosplay, memberikan bobot nilai pada masing - masing kriteria, kemudian melakukan perhitungan dengan rumus yang digunakan oleh masing masing metode.

Berikut adalah tabel IX yang merupakan tabel kriteria juri dan nilai bobot pada metode SAW

TABEL IX

KrITERIA JURI DAN NILAI BOBOT PADA METODE SAW

\begin{tabular}{|l|l|l|}
\hline Kode & \multicolumn{1}{|c|}{ Kriteria } & Bobot \\
\hline C1 & Pengalaman menjuri & 0.4 \\
\hline C2 & Pengalaman membuat kostum & 0.1 \\
\hline C3 & Pengalaman modeling & 0.3 \\
\hline C4 & Pengalaman pentas panggung & 0.2 \\
\hline
\end{tabular}

Nilai bobot kriteria pada metode simple additive weight yang didapatkan dari data survey tingkat kepentingan yang dimiliki oleh perusahaan, digunakan untuk menghitung nilai bobot masing - masing juri. Pemberian nilai bobot pada masing - masing juri perlu dilakukan terlebih dulu seperti tertera pada tabel $\mathrm{X}$ berikut.

TABEL X

BOBOT NILAI SAW SETIAP JURI TERHADAP KRITERIA

\begin{tabular}{|l|c|c|c|c|}
\hline Nama Juri & C1 & C2 & C3 & C4 \\
\hline Erlan & 1 & 2 & 1 & 3 \\
\hline Kaze & 1 & 3 & 2 & 3 \\
\hline Lola & 2 & 1 & 3 & 1 \\
\hline Moel & 3 & 1 & 1 & 2 \\
\hline Rian & 4 & 4 & 3 & 1 \\
\hline Total & $\mathbf{4}$ & $\mathbf{4}$ & $\mathbf{3}$ & $\mathbf{3}$ \\
\hline
\end{tabular}


Kemudian Data pada tabel $\mathrm{X}$ diatas akan dinormalisasikan. Dimana nilai normalisasi didapatkan dengan melakukan pembagian antara setiap nilai dengan total masing - masing kolom. Hasil dari Normalisasi Bobot ini dapat dilihat pada tabel XI

\section{TABEL XI}

HASIL NoRMALISASI BobOT NILAI SAW SETIAP JURI TERHADAP KRITERIA

\begin{tabular}{|l|l|l|l|l|}
\hline Nama Juri & \multicolumn{1}{|c|}{ C1 } & \multicolumn{1}{|c|}{ C2 } & \multicolumn{1}{|c|}{ C3 } & \multicolumn{1}{c|}{ C4 } \\
\hline Erlan & 0.25 & 0.5 & 0.3333 & 1 \\
\hline Kaze & 0.25 & 0.75 & 0.6667 & 1 \\
\hline Lola & 0.5 & 0.25 & 1 & 0.3333 \\
\hline Moel & 0.75 & 0.25 & 0.3333 & 0.6667 \\
\hline Rian & 1 & 1 & 1 & 0.3333 \\
\hline
\end{tabular}

Hasil normalisasi yang didapatkan pada tabel XI, kemudian dikalikan dengan tabel bobot nilai kriteria (tabel VII). Hasil perkalian yang menjadi hasil akhir perhitungan dapat dilihat pada tabel XII berikut.

TABEL XII

HASIL AKHIR NILAI Bobot JURI METOde SAW

\begin{tabular}{|l|l|l|l|l|c|}
\hline Nama Juri & C1 & \multicolumn{1}{|c|}{ C2 } & C3 & \multicolumn{1}{c|}{ C4 } & Total \\
\hline Erlan & 0.1 & 0.05 & 0.1 & 0.2 & $\mathbf{0 . 4 5 0 0}$ \\
\hline Kaze & 0.1 & 0.075 & 0.2 & 0.2 & $\mathbf{0 . 5 7 5 0}$ \\
\hline Lola & 0.2 & 0.025 & 0.3 & 0.0667 & $\mathbf{0 . 5 9 1 6}$ \\
\hline Moel & 0.3 & 0.025 & 0.1 & 0.1333 & $\mathbf{0 . 5 5 8 3}$ \\
\hline Rian & 0.4 & 0.1 & 0.3 & 0.0667 & $\mathbf{0 . 8 6 6 6}$ \\
\hline
\end{tabular}

Apabila data hasil akhir perhitungan metode SAW diurutkan maka peringkat pertama ditempati oleh Rian dengan nilai 0.8666 , dilanjut dengan Lola (0.5916), Kaze (0.5750), Moel (0.5583), dan Erlan (0.4500).

Sedangkan pada metode AHP, perlu dibentuknya struktur hirarki permasalahan terlebih dulu untuk mendapatkan gambaran dan tingkatan perhitungan hirarki. Struktur hirarki dapat dilihat pada gambar 5 Struktur Hierarki Permasalahan berikut

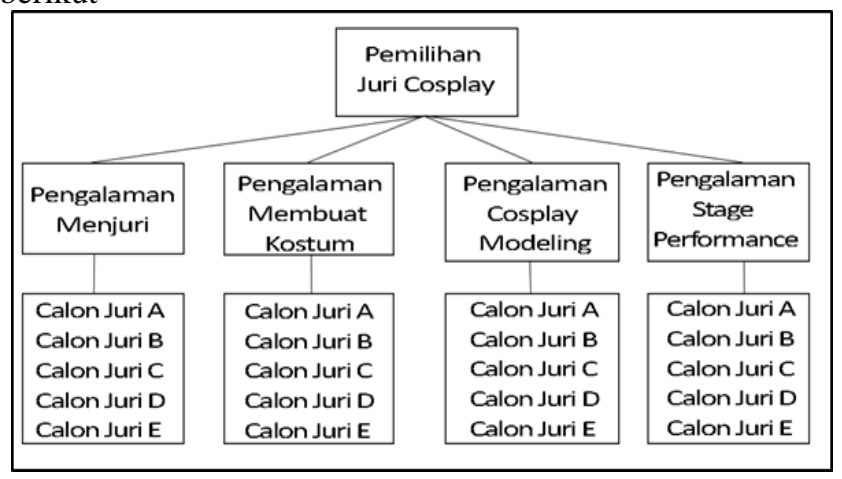

Gambar 5. Struktur Hirarki Permasalahan

Pada setiap kriteria dilakukan pemberian bobot nilai untuk menentukan tingkat kepentingan masing - masing kriteria, dimana pada bagian teratas hirarki yang sekaligus menjadi tujuan dari permasalahan ini adalah pemilihan juri cosplay, diikuti dengan tingkat pertama yaitu kriteria yang digunakan untuk memberikan penilaian pada calon juri, dan tingkat kedua yang berisikan nama - nama calon yang akan dibandingkan satu sama lain.

Data yang digunakan sebagai nilai bobot kriteria pada metode AHP didapatkan dari data survey yang dilakukan oleh perusahaan terkait dengan kemampuan yang lebih diperlukan sebagai juri cosplay. Nilai bobot metode AHP dapat dilihat pada tabel XIII berikut.

TABEL XIII

KRITERIA JURI DAN NILAI BOBOT PADA METODE AHP

\begin{tabular}{|l|l|l|l|l|}
\hline \multicolumn{1}{|c|}{ Kriteria } & \multicolumn{1}{c|}{ E } & \multicolumn{1}{|c|}{ C } & \multicolumn{1}{|c|}{ M } & \multicolumn{1}{|c|}{} \\
\hline Pengalaman Menjuri (E) & 1 & 4 & 2 & 3 \\
\hline Pengalaman Membuat (C) & $1 / 4$ & 1 & $1 / 2$ & $1 / 2$ \\
\hline Pengalaman Modeling (M) & $1 / 2$ & 2 & 1 & 2 \\
\hline $\begin{array}{l}\text { Pengalaman Pentas } \\
\text { Panggung (P) }\end{array}$ & $1 / 3$ & 2 & $1 / 2$ & 1 \\
\hline
\end{tabular}

Dari tabel XIII kemudian dilakukan perhitungan untuk mendapatkan supermatriks dari tabel tersebut yang didapatkan dengan melakukan pembagian setiap nilai dengan total masing-masing kolom. Terakhir dilakukan penjumlahan pada setiap barisnya dan membagi dengan banyaknya kriteria untuk mendapatkan nilai rata - rata atau yang disebut eigen (lihat tabel XIV).

TABEL XIV

SUPERMATRIKS NILAI KRITERIA DAN BobOT JURI PADA METODE AHP

\begin{tabular}{|l|c|c|c|c|c|}
\hline \multicolumn{1}{|c|}{ Kriteria } & E & C & M & P & eigen \\
\hline $\begin{array}{l}\text { Pengalam } \\
\text { an } \\
\text { Menjuri } \\
\text { (E) }\end{array}$ & 0.4807 & 0.4444 & 0.5000 & 0.4615 & 0.4716 \\
\hline $\begin{array}{l}\text { Pengalam } \\
\text { an } \\
\text { Membuat } \\
\text { (C) } \\
\text { Costplay }\end{array}$ & 0.1201 & 0.1111 & 0.1250 & 0.0769 & 0.1082 \\
\hline $\begin{array}{l}\text { Pengalam } \\
\text { an } \\
\text { Modeling } \\
\text { (M) }\end{array}$ & 0.2403 & 0.2222 & 0.2500 & 0.3076 & 0.2550 \\
\hline $\begin{array}{l}\text { Pengalam } \\
\text { an Pentas } \\
\text { Panggung } \\
\text { (P) }\end{array}$ & 0.1586 & 0.2222 & 0.1250 & 0.1538 & 0.1649 \\
\hline
\end{tabular}

Langkah selanjutnya dari metode AHP adalah memberikan bobot nilai pada masing - masing juri dengan perbandingan satu juri dengan yang lainnya. Nilai bobot yang diberikan akan melalui proses perhitungan yang sama seperti tabel kriteria diatas sebelumnya, dimana untuk mendapatkan hasil akhir akan dicari nilai eigen pada setiap kriteria terhadap juri. Tahapan perhitungan pada kriteria menjuri dilakukan juga pada setiap kriteria yang ada untuk mendapatkan hasil eigen dari masing - masing kriteria. 
Adapun Hasil Akhir perhitungan metode AHP dapat dilihat pada tabel XV dibawah ini.

TABEL XV

HASIL AKHIR PERHITUNGAN METODE AHP

\begin{tabular}{|l|l|l|l|l|l|}
\hline Calon & $\begin{array}{c}\text { Experi } \\
\text { ence }\end{array}$ & $\begin{array}{c}\text { Creatin } \\
\boldsymbol{g}\end{array}$ & $\begin{array}{c}\text { Modelin } \\
\boldsymbol{g}\end{array}$ & $\begin{array}{c}\text { Perform } \\
\text { ing }\end{array}$ & Result \\
\hline Erlan & 0.0441 & 0.018 & 0.0277 & 0.0630 & $\mathbf{0 . 1 5 2 8}$ \\
\hline Kaze & 0.0311 & 0.026 & 0.0658 & 0.0478 & $\mathbf{0 . 1 7 0 7}$ \\
\hline Lola & 0.0827 & 0.0083 & 0.0707 & 0.0136 & $\mathbf{0 . 1 7 5 3}$ \\
\hline Moel & 0.1161 & 0.0111 & 0.0189 & 0.0217 & $\mathbf{0 . 1 6 7 8}$ \\
\hline Rian & 0.1973 & 0.0445 & 0.0714 & 0.0183 & $\mathbf{0 . 3 3 1 5}$ \\
\hline
\end{tabular}

Kedua hasil akhir yang diperoleh dari perhitungan masing - masing metode ditampilkan bersamaan dalam bentuk peringkat dengan urutan nilai terbesar hingga terkecil. Penerapan hasil akhir pada sistem diperlihatkan pada gambar 6 tentang Hasil Perhitungan Akhir kedua yaitu Metode AHP dan SAW berikut ini

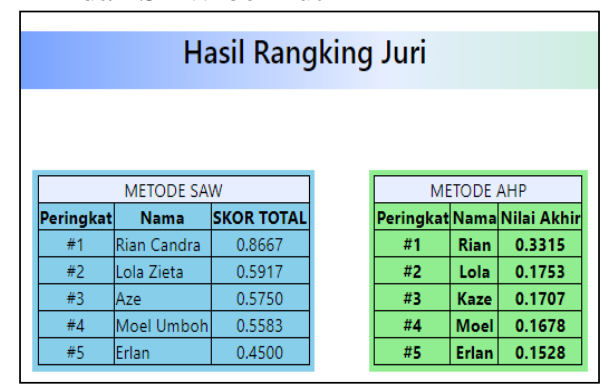

Gambar 6. Hasil Perhitungan Akhir Masing - Masing Metode Pada Sistem

Beberapa tampilan fitur sistem organizer selain fitur sistem rekomendasi yaitu, fitur pembuatan event baru dan pembuatan jadwal diatas akan dilampirkan sebagai berikut.

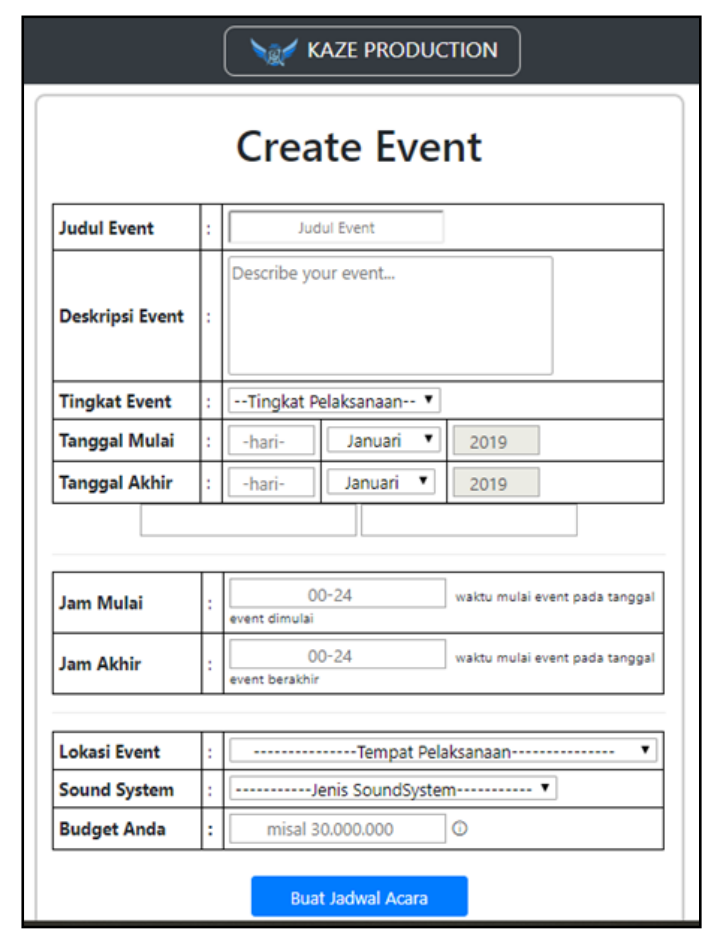

Gambar 7. Tampilan Fitur Pembuatan Event Baru pada Member

Tampilan Fitur Pembuatan Event Baru pada Member pada gambar 7 merupakan tampilan halaman dimana member dapat membuat event baru untuk didaftarkan ke dalam sistem. Format tampilan berupa form standar dengan meminta inputan data mulai dari judul, deskripsi, tingkat pelaksanaan event (daerah / nasional), tanggal mulai dan akhir event, jam mulai dan akhir event, lokasi event, jenis sound system yang digunakan, hingga biaya yang disiapkan oleh member untuk membiayai event yang dibuat.

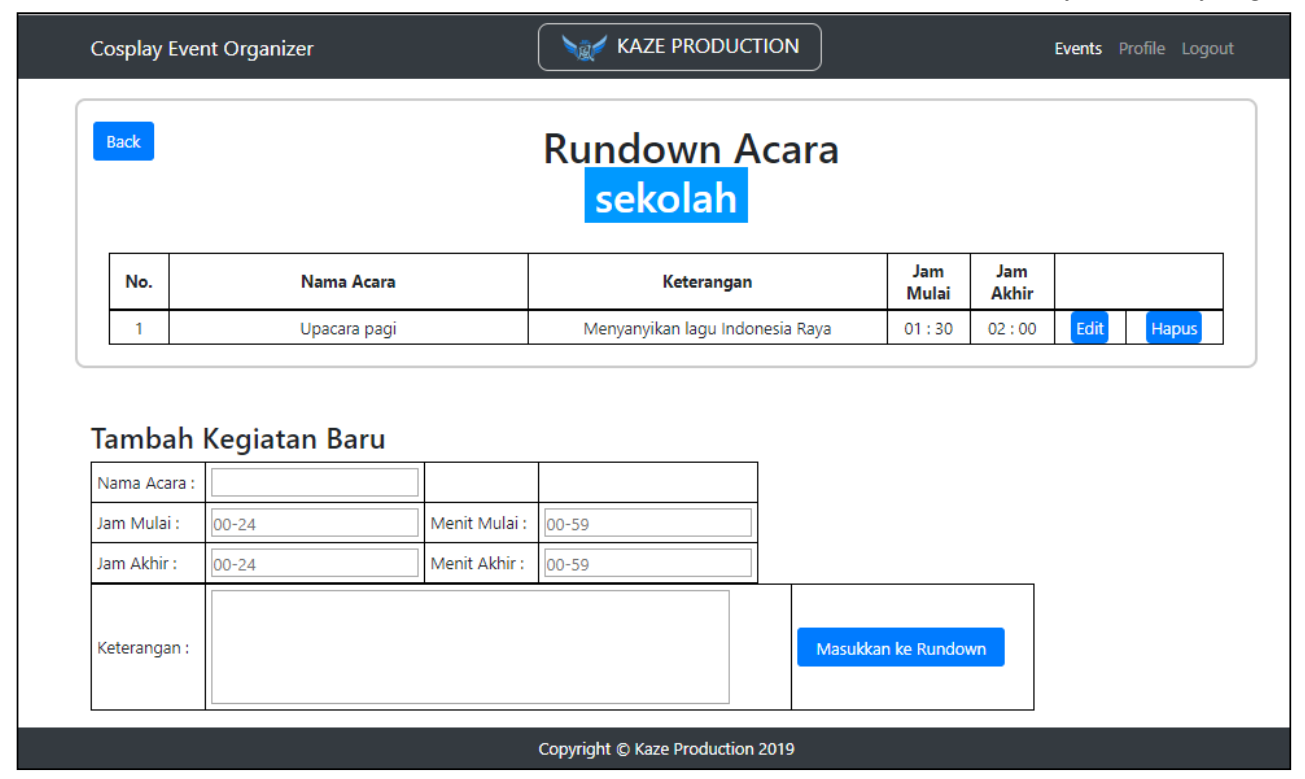

Gambar 8. Tampilan Fitur Jadwal Acara pada Event Member 
Tampilan Fitur Jadwal Acara pada Event Member pada gambar 8 diatas merupakan tahap lanjutan setelah member berhasil mendaftarkan event pada gambar 7. Pada tampilan ini member dapat membuat penjadwalan berkaitan dengan rangkaian acara kegiatan yang ingin diadakan dalam event tersebut. Data yang diperlukan sebagai masukan adalah nama acara, jam mulai, jam akhir, hingga keterangan singkat yang dapat menjelaskan kegiatan tersebut dengan singkat. Selanjutnya akan dibahas mengenai fitur - fitur yang diberikan untuk admin sebagai pengelola sistem dari pihak perusahaan. Fitur yang dimiliki antara lain, mengorganisir event yang dibuat oleh member, mengubah data nilai performa juri yang digunakan untuk melakukan perhitungan skor juri pada kedua metode yang diterapkan (AHP dan SAW).

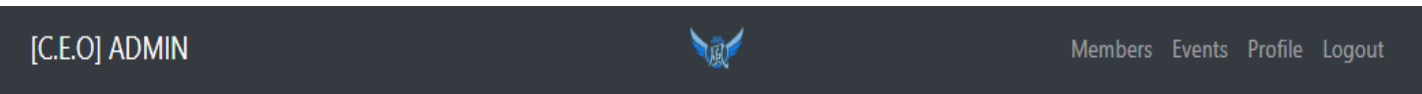

\section{Kembal}

\section{Daftar Event Yang Terdaftar}

\begin{tabular}{|c|c|c|c|c|}
\hline No. & Nama Event & Tanggal Submit & Status Event & Detail \\
\hline 1 & sekolah & $2019-04-0118: 13: 50$ & Mohon menunggu untuk dievaluasi & Detail \\
\hline 2 & Ballroom & $2019-04-0118: 20: 11$ & Mohon menunggu untuk dievaluasi & Detail \\
\hline 3 & Stadium & $2019-04-0118: 22: 44$ & Mohon menunggu untuk dievaluasi & Detail \\
\hline 4 & Mallerezasdasd & $2019-04-0118: 25: 38$ & Jadwal acara tidak ada / belum lengkap. & Detail \\
\hline 5 & Lomba cosplay kota Bandung & $2019-04-0213: 23: 41$ & Mohon menunggu untuk dievaluasi & Detail \\
\hline 7 & aaa & $2019-04-1422: 31: 18$ & Mohon menunggu untuk dievaluasi & Detail \\
\hline
\end{tabular}

Gambar 9. Halaman Admin Mengorganisasi Event

Halaman Admin Mengorganisasi Event pada gambar 9 menampilkan seluruh data event yang terdaftar dalam sistem dengan status eventnya masing - masing. Admin dapat melakukan evaluasi dengan memilih menu detail pada event yang akan dievaluasi. Pengevaluasian ini perlu dilakukan oleh admin untuk memastikan bahwa event yang dibuat oleh member telah terisi dengan lengkap sehingga tidak menimbulkan hal-hal yang akan menghambat proses pelaksanaannya.

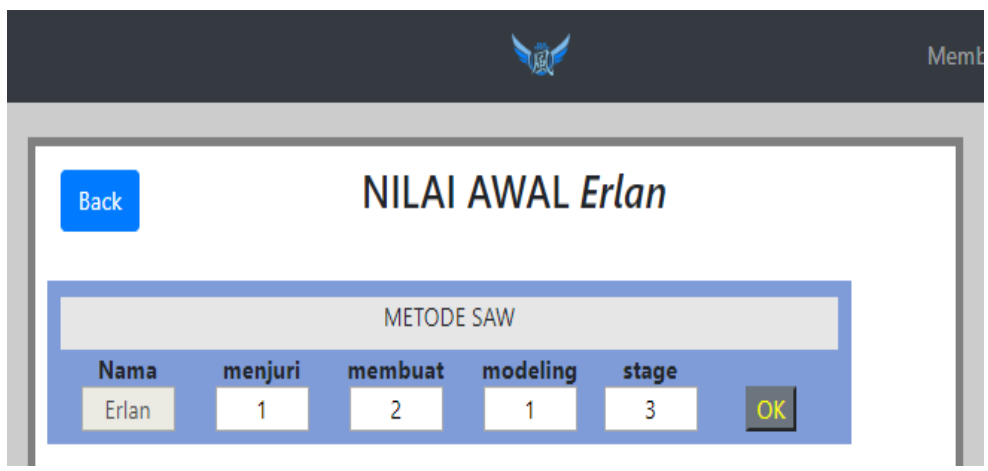

Gambar 10. Halaman untuk Mengubah Nilai Performa pada Metode SAW 
Gambar10 merupakan tampilan dimana admin melakukan perubahan data nilai performa juri misalnya nilai dari Erlan, nilai kita umpamakan sebagai rating bintang pada umumnya, Erlan mendapat bintang 1 pada kriteria menjuri, bintang 2 pada membuat kostum, bintang 1 pada modeling, dan bintang 3 pada performa panggung. Data ini kemudian akan dihitung otomatis oleh sistem dan hasil akhirnya akan ditampilkan pada ranking juri. Hasil akhir peringkat performa juri dengan perhitungan metode SAW dapat dilihat seperti pada gambar 11 tentang Hasil Peringkat Juri dengan Perhitungan Metode SAW

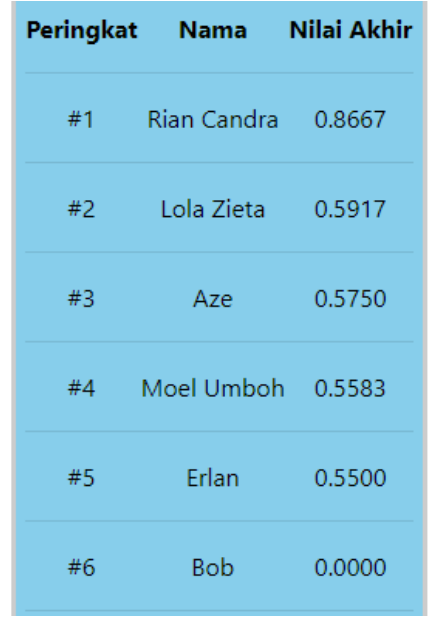

Gambar 11. Hasil Peringkat Juri dengan Perhitungan Metode SAW

Dapat dilihat bahwa peringkat juri diurutkan berdasarkan hasil nilai yang terbesar hingga terkecil. Peringkat pertama ditempati oleh Rian Candra dengan perolehan nilai 0.8667, diikuti oleh Lola dengan perolehan nilai 0.5917, dan seterusnya. Hasil peringkat ini kemudian akan ditampilkan pada layar klien saat klien melakukan pemilihan juri yang akan diundang ke dalam acara yang dibuatnya.

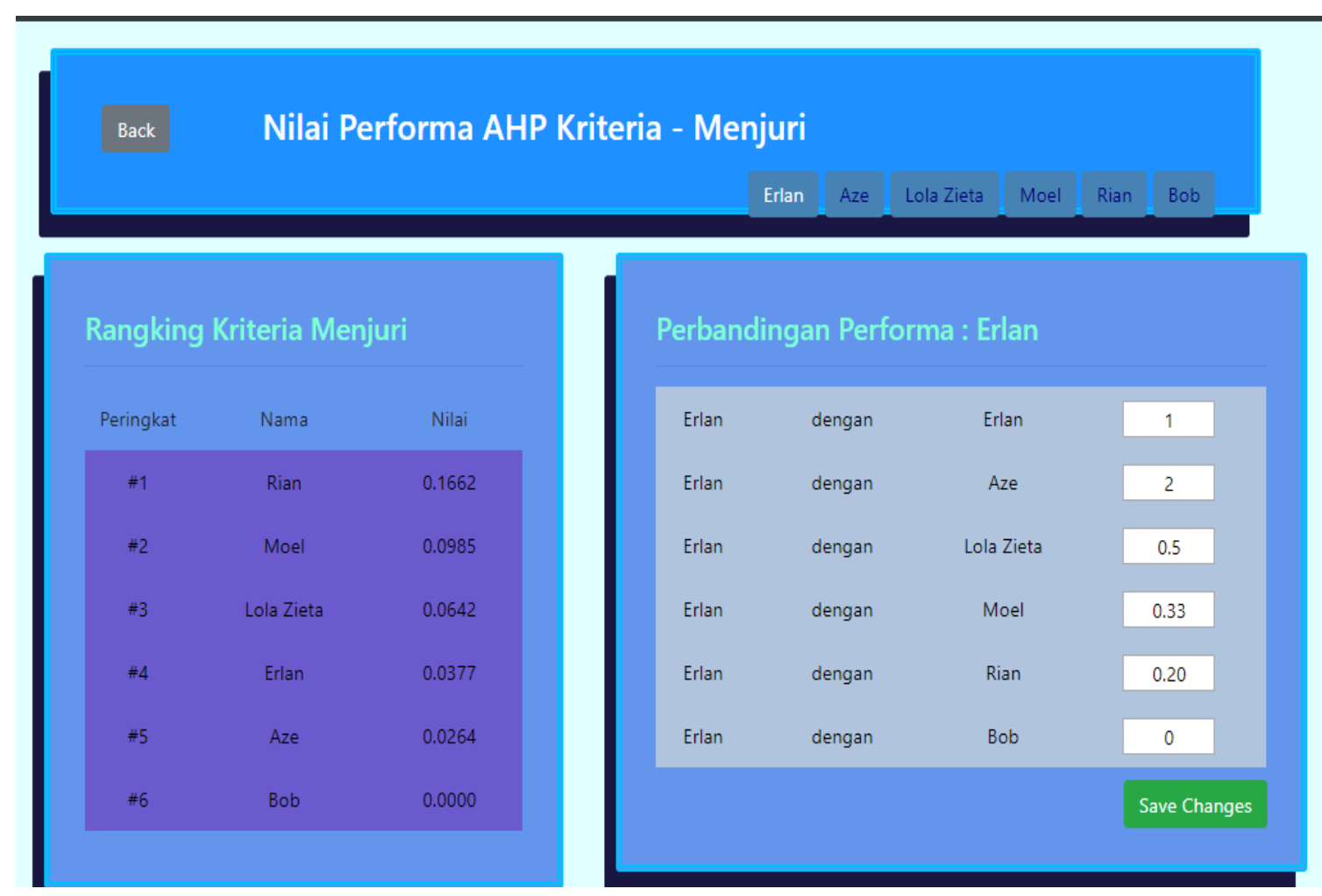

Gambar 12. Halaman untuk Mengubah Nilai Performa pada Metode AHP. 
Halaman untuk Mengubah Nilai Performa pada Metode AHP seperti terlihat pada gambar .12 merupakan tampilan untuk mengubah nilai performa juri pada metode AHP. Dalam metode ini proses pemberian nilai dilakukan dengan cara perbandingan tingkat kepentingan satu juri dengan juri lainnya. Pada fitur metode AHP peringkat langsung ditampilkan pada masing - masing kriteria, dan perubahan rangking dilakukan secara otomatis setiap data mengalami perubahan.

\section{B. Hasil Pengujian Terhadap Sistem (Black Box Testing)}

Pengujian pada sistem dilakukan untuk mengetahui apakah sistem telah berjalan sesuai dengan target yang telah ditetapkan. Beberapa pengujian yang dilakukan pada sistem adalah pengujian sign up, login, create new event, tambah juri, evaluasi event, pengubahan performa juri pada metode AHP dan SAW.

Pengujian pada fitur sign up bertujuan untuk mengetahui apakah pengunjung dapat melakukan pendaftaran sebagai pengguna aplikasi agar terdaftar ke dalam sistem. Hasil dan harapan dari pengujian pada fitur sign up dapat dilihat pada tabel berikut.

Tujuan dari pengujian fitur create new event adalah untuk memastikan bahwa pengguna yang terdaftar dapat membuat kegiatan acara baru dan mendaftarkannya ke dalam sistem tanpa adanya kendala. Hasil pengujian pada fitur create new event dapat dilihat pada tabel XVI dibawah ini.

TABEL XVI

Pengujian Fitur CREATE New Event

\begin{tabular}{|c|c|c|}
\hline Test case & $\begin{array}{l}\text { Hasil yang } \\
\text { diharapkan }\end{array}$ & Hasil pengujian \\
\hline $\begin{array}{l}\text { Member memilih } \\
\text { menu 'create new } \\
\text { event'. }\end{array}$ & $\begin{array}{l}\text { Sistem akan } \\
\text { menampilkan } \\
\text { halaman berisi } \\
\text { form pembuatan } \\
\text { event baru. }\end{array}$ & $\begin{array}{l}\text { Sistem } \\
\text { menampilkan } \\
\text { halaman berisi } \\
\text { form pembuatan } \\
\text { event baru. }\end{array}$ \\
\hline $\begin{array}{l}\text { Member mengisi } \\
\text { semua kolom } \\
\text { sesuai dengan } \\
\text { format dan } \\
\text { menekan tombol } \\
\text { create event. }\end{array}$ & $\begin{array}{l}\text { Sistem akan } \\
\text { mencatat event } \\
\text { baru yang di } \\
\text { submit dan akan } \\
\text { menampilkan } \\
\text { pesan bahwa event } \\
\text { berhasil dibuat. }\end{array}$ & $\begin{array}{l}\text { Sistem mencatat } \\
\text { event baru yang di } \\
\text { submit dan } \\
\text { menampilkan } \\
\text { pesan bahwa event } \\
\text { berhasil dibuat. }\end{array}$ \\
\hline
\end{tabular}

Pengujian fitur tambah juri bertujuan untuk mengetahui apakah pengguna dapat memilih juri dari daftar yang ada untuk ditambahkan ke dalam suatu acara. Tabel XVII berikut merupakan tabel Hasil Pengujian Fitur Tambah juri

TABEL XVII

PENGUJIAN FITUR TAMBAH JURI

\begin{tabular}{|c|c|c|}
\hline Test case & $\begin{array}{l}\text { Hasil yang } \\
\text { diharapkan }\end{array}$ & Hasil pengujian \\
\hline $\begin{array}{l}\text { Admin memilih } \\
\text { menu detail pada } \\
\text { suatu event yang }\end{array}$ & $\begin{array}{l}\text { Sistem akan } \\
\text { menampilkan form } \\
\text { detail mengenai }\end{array}$ & $\begin{array}{l}\text { Sistem } \\
\text { menampilkan } \\
\text { form detail } \\
\end{array}$ \\
\hline
\end{tabular}

\begin{tabular}{|c|c|c|}
\hline Test case & $\begin{array}{l}\text { Hasil yang } \\
\text { diharapkan }\end{array}$ & Hasil pengujian \\
\hline terdaftar. & $\begin{array}{l}\text { rincian mengenai } \\
\text { event yang dipilih. }\end{array}$ & $\begin{array}{l}\text { mengenai } \\
\text { rincian } \\
\text { mengenai event } \\
\text { yang dipilih. }\end{array}$ \\
\hline $\begin{array}{l}\text { Admin melakukan } \\
\text { perubahan pada } \\
\text { status event dan } \\
\text { memilih tombol } \\
\text { evaluasi event. }\end{array}$ & $\begin{array}{l}\text { Sistem akan } \\
\text { mencatat } \\
\text { perubahan status } \\
\text { pada event, dan } \\
\text { menampilkan } \\
\text { kembali halaman } \\
\text { daftar event. }\end{array}$ & $\begin{array}{l}\text { Sistem mencatat } \\
\text { perubahan status } \\
\text { pada event, dan } \\
\text { menampilkan } \\
\text { kembali } \\
\text { halaman daftar } \\
\text { event. }\end{array}$ \\
\hline
\end{tabular}

Pengujian fitur evaluasi events dilakukan untuk mengetahui apakah fitur telah berjalan sesuai dengan target yang diharapkan. Hasil dari pengujian dapat dilihat pada tabel XVIII berikut.

TABEL XVIII

Pengujian Fitur Evaluasi Event

\begin{tabular}{|c|c|c|}
\hline Test case & $\begin{array}{c}\text { Hasil yang } \\
\text { diharapkan }\end{array}$ & Hasil pengujian \\
\hline $\begin{array}{l}\text { Member } \\
\text { memasukkan } \\
\text { format tanggal } \\
\text { yang salah. }\end{array}$ & $\begin{array}{l}\text { Sistem akan } \\
\text { menampilkan } \\
\text { pesan bahwa } \\
\text { format tanggal } \\
\text { yang dimasukkan } \\
\text { tidak sesuai. }\end{array}$ & $\begin{array}{l}\text { Sistem } \\
\text { menampilkan } \\
\text { pesan bahwa } \\
\text { format tanggal } \\
\text { yang dimasukkan } \\
\text { tidak sesuai. }\end{array}$ \\
\hline $\begin{array}{l}\text { Member } \\
\text { memasukkan } \\
\text { nominal budget } \\
\text { yang kurang dari } \\
\text { biaya awal. }\end{array}$ & $\begin{array}{l}\text { Sistem akan } \\
\text { menampilkan } \\
\text { pesan bahwa } \\
\text { budget yang } \\
\text { diinput kurang dari } \\
\text { biaya awal. }\end{array}$ & $\begin{array}{l}\text { Sistem } \\
\text { menampilkan } \\
\text { pesan bahwa } \\
\text { budget yang } \\
\text { diinput kurang dari } \\
\text { biaya awal. }\end{array}$ \\
\hline $\begin{array}{l}\text { Member tidak } \\
\text { mengisi sebagian } \\
\text { kolom. }\end{array}$ & $\begin{array}{l}\text { Sistem akan } \\
\text { menampilkan } \\
\text { pesan bahwa ada } \\
\text { kolom yang belum } \\
\text { terisi. }\end{array}$ & $\begin{array}{l}\text { Sistem } \\
\text { menampilkan } \\
\text { pesan bahwa ada } \\
\text { kolom yang belum } \\
\text { terisi. }\end{array}$ \\
\hline $\begin{array}{l}\text { Member memillih } \\
\text { menu tambah juri. }\end{array}$ & $\begin{array}{l}\text { Sistem akan } \\
\text { menampilkan } \\
\text { halaman dengan } \\
\text { form pilihan juri. }\end{array}$ & $\begin{array}{l}\text { Sistem } \\
\text { menampilkan } \\
\text { halaman dengan } \\
\text { form pilihan juri. }\end{array}$ \\
\hline $\begin{array}{l}\text { Member memilih } \\
\text { salah satu juri yang } \\
\text { ada pada pilihan } \\
\text { dan memilih save } \\
\text { changes. }\end{array}$ & $\begin{array}{l}\text { Sistem akan } \\
\text { mencatat } \\
\text { perubahan event ke } \\
\text { dalam database } \\
\text { dan kembali } \\
\text { menampilkan } \\
\text { halaman detail } \\
\text { event yang } \\
\text { bersangkutan. }\end{array}$ & $\begin{array}{l}\text { Sistem mencatat } \\
\text { perubahan event ke } \\
\text { dalam database } \\
\text { dan kembali } \\
\text { menampilkan } \\
\text { halaman detail } \\
\text { event yang } \\
\text { bersangkutan. }\end{array}$ \\
\hline
\end{tabular}

\section{KESIMPULAN}

Sistem yang dibangun dapat membantu perusahaan dalam perubahan proses bisnis yang terkomputerisasi dan memudahkan pengorganisiran data - data yang disimpan, 
juga meminimalisir terjadinya kesalahan - kesalahan yang disebabkan oleh manusia. Sistem yang dikembangkan juga dapat melakukan perhitungan nilai performa juri dengan masing - masing metode dengan langsung, sehingga data dapat berubah secara bersamaan pada sisi admin dan juga member.

Sedangkan dari sudut pandang member sebagai pengguna dapat merasakan kemudahan baik sebagai pemula dalam membuat event atau pun yang ahli, melakukan pembuatan event cosplay. Terdapat Informasi yang singkat namun jelas, rincian biaya yang dihitung otomatis oleh sistem, hingga adanya fitur untuk membuat jadwal pada hari setiap event yang diadakan.

Dengan ditambahkannya fitur sistem rekomendasi juri, diharapkan dapat memberikan gambaran kepada member mengenai kemampuan juri yang baik secara umum seperti apa, peringkat juri berdasarkan kemampuan masing masing juri, dan sebagai pengguna yang membuat event dapat dibantu untuk mengambil keputusan juri yang akan dipilih untuk event yang diadakannya.

Penerapan metode SAW dan AHP yang dilakukan pada fitur sistem rekomendasi menghasilkan pereandingan yang unik, karena pada satu sisi, perhitungan metode SAW menunjukan nilai performa data juri dengan singkat, padat, dan jelas. Dan perhitungan metode AHP apabila diumpamakan dapat dikatakan sebagai metode senior dari metode SAW karena pada prosesnya dilakukan tahapan tahapan yang lebih detail dan mendalam.

Perbandingan hasil perhitungan kedua metode menghasilkan nilai performa yang bila diurutkan secara nilai terbesar hingga terkecil, yang memiliki urutan peringkat yang sama. Dimana dalam contoh kasus beberapa gambar diatas sebelumnya, Rian menempati peringkat satu pada kedua hasil perhitungan metode, kemudian Lola, Kaze, Moel, dan Erlan. Dengan diberikannya perbandingan kedua metode ini, diharapkan dapat membuat pengguna yang akan memilih calon juri event, menjadi lebih yakin terhadap pilihan juri yang dilakukan sesuai dengan jenis event cosplay.

\section{DAFTAR PUSTAKA}

[1] Priyanto Hidayatullah, Pemrograman WEB: HTML, JavaScript, XAMP, MySQL, PHP. Bandung: INFORMATIKA, 2017.

[2] I Dewa Ayu Eka Yuliani, "Sistem Pendukung Keputusan Pemilihan Karyawan Terbaik Dengan Metode Analytical Hierarchy Process," Jurnal Sisfotenika, vol. 3, no. 2, Juli 2013.

[3] (2010, Azmie. Business Process Modeling Notation (BPMN).website (online) Tersedia: http://mystroberi.blogspot.com/2010/10/business-process-modelingnotasi-bpmn.html

[4] (2018) M. Irwan. Black box and white box testing. Website Tersedia: http://tkjpnup.blogspot.co.id/2013/12/black-box-testingdan-white-box-testing.html

[5] Zhuge Kamiya, Kriteria Penilaian Cosplay Competition, 2012

[6] Leni Natalia Zulita, "Sistem Pendukung Keputusan Menggunakan Metode SAW Untuk Penilaian Dosen Berprestasi (Studi Kasus di Universitas X)," Jurnal Media Infotama, vol. 9, no. 3, September 2012.

[7] A. Suhenandar and Hariman Gunadi, Visual modeling menggunakan UML dan rational rose, 1st ed. Bandung, Indonesia: Informatika, 2002.

[8] DPD IPBI Jatim, Menjadi Seorang Juri, 2014.

[9] Cahyo Shobirin, Kelebihan dan Kekurangan Sistem Pendukung Keputusan, 2015.

[10] Informatika, Visual Modeling Menggunakan UML dan Ratiional Rose, Bandung, 2002.

[11] Srinivas Nidhra, Jagruthi Dondeti, Black Box and White Box Testing Techniques - A Literature Review, Pg. 33, International Journal od Embedded Systems and Applications (IJESA) Vol.2, No.2, June 2012. 